\title{
PENYULUHAN PENULISAN SURAT LAMARAN PEKERJAAN DAN PRAKTIK PENULISANNYA PADA SISWA SMA KORPRI BANJARMASIN
}

\author{
Novi Shintia ${ }^{1}$, Tarman Effendi ${ }^{2}$, Padli $^{3}$, Rika Novyanti ${ }^{2}$ \\ Politeknik Negeri Banjarmasin ${ }^{1234}$ \\ Novi221177@poliban.ac.id ${ }^{I}$ \\ tarmaneffendi@poliban.ac.id ${ }^{2}$ \\ Padlipoliban@gmail.com ${ }^{3}$ \\ ovy_green@yahoo.com ${ }^{4}$
}

\begin{abstract}
The purpose of community service includes (1) providing information on job openings, official related information, information from advertisements, from other sources, and without information, (2) providing information regarding how to apply for a job, especially applying for a job over the telephone and applying for a job through application letter, (3) providing information about the job application letter, especially with regard to understanding job application letters, job application letter formats, and sections of application letter, and (4) provides information on how to send application letters, application which is based on official information, information from advertisements, information from other sources, and without information.

This activity was carried out on Wednesday, August 28, 2019, at the Korpri Banjarmasin High School, Jalan Tanjung I Perumnas Kayutangi Blok IV Banjarmasin. The number of participants is 20 people. Counseling is delivered using the lecture method, questions and answers, and practice of receiving application letters by students.

The results of the implementation issued about application letter and its practice on Banjarmasin Korpri High School students, specifically in third year students as participants, are (1) students can know well about job vacancy information, find official information, information from advertisements, information from other sources, and without information, (2) students can know well how to apply for a job through a job application letter, (3) students can search well for a job application letter, especially with regard to understanding job application letters, job application letter functions, formatting job application letters, and parts of job application letters, and (4) students can write job application letters with information from other sources, and without being informed
\end{abstract}

Keywords: letter writing, letter form, application letter

\begin{abstract}
ABSTRAK
Tujuan pengabdian kepada masyarakat berupa penyuluhan penulisan surat lamaran pekerjaan dan praktik penulisannya pada siswa SMA Korpri Banjarmasin ini adalah (1) memberikan informasi mengenai lowongan pekerjaan, terutama informasi resmi, informasi dari iklan, informasi dari sumber lain, dan tanpa informasi, (2) memberikan informasi mengenai cara melamar suatu pekerjaan, terutama melamar pekerjaan melalui telepon dan melamar pekerjaan melalui surat lamaran pekerjaan, (3) memberikan
\end{abstract}


informasi mengenai surat lamaran pekerjaan, terutama berkenaan dengan pengertian surat lamaran pekerjaan, fungsi surat lamaran pekerjaan, format surat lamaran pekerjaan, dan bagian-bagian surat lamaran pekerjaan, dan (4) memberikan informasi mengenai cara menulis surat lamaran pekerjaan, terutama surat lamaran pekerjaan berdasarkan informasi resmi, informasi dari iklan, informasi dari sumber lain, dan tanpa informasi.

Kegiatan ini dilaksanakan pada hari Rabu, 28 Agustus 2019, bertempat di SMA Korpri Banjarmasin, Jalan Tanjung I Perumnas Kayutangi Blok IV Banjarmasin. Jumlah siswa (sebagai peserta penyuluhan) sebanyak 20 orang. Tim penyuluh sebanyak 4 orang. Mahasiswa yang ikut penyuluhan sebanyak 2 orang. Penyuluhan disampaikan dengan metode ceramah, tanya jawab, dan praktik penulisan surat lamaran oleh para siswa (sebagai peserta penyuluhan).

Berdasarkan hasil pelaksanaan penyuluhan penulisan surat lamaran pekerjaan dan praktik penulisannya pada siswa SMA Korpri Banjarmasin, khususnya pada siswa kelas III sebagai peserta penyuluhan, dapat dikemukakan bahwa (1) siswa dapat mengetahui dengan baik mengenai informasi lowongan pekerjaan, terutama informasi resmi, informasi dari iklan, informasi dari sumber lain, dan tanpa informasi, (2) siswa dapat mengetahui dengan baik mengenai cara melamar suatu pekerjaan, terutama melamar pekerjaan melalui telepon dan melamar pekerjaan melalui surat lamaran pekerjaan, (3) siswa dapat mengetahui dengan baik mengenai surat lamaran pekerjaan, terutama berkenaan dengan pengertian surat lamaran pekerjaan, fungsi surat lamaran pekerjaan, format surat lamaran pekerjaan, dan bagian-bagian surat lamaran pekerjaan, dan (4) siswa dapat menulis surat lamaran pekerjaan dengan baik, terutama surat lamaran pekerjaan berdasarkan informasi resmi, informasi dari iklan, informasi dari sumber lain, dan tanpa informasi.

Kata Kunci: penulisan surat, bentuk surat, surat lamaran

\section{PENDAHULUAN}

Penulisan surat lamaran pekerjaan sangat diperlukan bagi (seorang) siswa, termasuk siswa SMA Korpri Banjarmasin. Bagi seorang siswa, ketika lulus dari sekolah (SMA), bisa melanjutkan ke perguruan tinggi, bisa pula melamar pekerjaan sesuai dengan bidang pekerjaan yang diinginkan. Dalam rangka melamar pekerjaan, salah satu yang perlu diketahui dan dilakukan oleh siswa yaitu menulis surat lamaran pekerjaan.

Selain menulis surat lamaran pekerjaan, yang juga perlu diketahui oleh siswa sebelumnya, yaitu mengenai surat lamaran pekerjaan, informasi lowongan pekerjaan, dan cara melamar suatu pekerjaan. Oleh karena itu, materi penyuluhan ini tidak hanya mengenai penulisan surat lamaran pekerjaan - sebelumnya juga disampaikan - berkenaan dengan surat lamaran pekerjaan, informasi lowongan pekerjaan, dan cara melamar suatu pekerjaan. Dengan demikian, diharapkan siswa kelak dapat mengajukan lamaran dengan baik serta dapat diterima bekerja sesuai dengan bidang pekerjaan yang diinginkan.

Permasalahan umum siswa SMA Korpri Banjarmasin, berkenaan dengan melamar pekerjaan, tentu saja bagaimana cara menulis surat lamaran pekerjaan. Hal tersebut sangat perlu diketahui oleh siswa, lebih-lebih kalau siswa tersebut sudah lulus dari sekolah dan ingin melamar pekerjaan sesuai dengan bidang pekerjaan yang diinginkan. Surat lamaran pekerjaan (biasanya) sangat 
berpengaruh bila siswa (setelah lulus) ingin melamar pekerjaan. Baik tidaknya atau benar tidaknya surat lamaran pekerjaan yang ditulis oleh siswa, dapat menentukan lulus tidaknya siswa dalam melamar pekerjaan tersebut. Dalam hal ini, terutama berkenaan dengan seleksi administrasi pada salah satu tahap seleksi dalam rangka melamar pekerjaan.

Selain itu, bisa pula terjadi bagi seorang siswa (setelah lulus) manakala melamar pekerjaan mengalami kesulitan untuk mengetahui informasi lowongan pekerjaan dan cara melamar suatu pekerjaan. Oleh karena itu, bagi seorang siswa, kalau sudah lulus dan ingin melamar pekerjaan siswa sudah mengetahui selain menulis surat lamaran pekerjaan (sebelumnya) juga mengetahui informasi lowongan pekerjaan dan cara melamar suatu pekerjaan. Dengan demikian, manakala siswa kelak mengajukan lamaran pekerjaan diharapkan dapat diterima bekerja sesuai dengan bidang pekerjaan yang diinginkan.

Tujuan kegiatan penyuluhan penulisan surat lamaran pekerjaan dan praktik penulisannya pada siswa SMA Korpri Banjarmasin ini adalah:

1. Memberikan informasi mengenai lowongan pekerjaan, terutama informasi resmi, informasi dari iklan, informasi dari sumber lain, dan tanpa informasi kepada siswa SMA Korpri Banjarmasin.

2. Memberikan informasi mengenai cara melamar suatu pekerjaan, terutama melamar pekerjaan melalui telepon dan melamar pekerjaan melalui surat lamaran pekerjaan kepada siswa SMA Korpri Banjarmasin.

3. Memberikan informasi mengenai surat lamaran pekerjaan, terutama berkenaan dengan pengertian surat lamaran pekerjaan, fungsi surat lamaran pekerjaan, format surat lamaran pekerjaan, dan bagian-bagian surat lamaran pekerjaan kepada siswa SMA Korpri Banjarmasin.

4. Memberikan informasi mengenai cara menulis surat lamaran pekerjaan, terutama surat lamaran pekerjaan berdasarkan informasi resmi, informasi dari iklan, informasi dari sumber lain, dan tanpa informasi kepada siswa SMA Korpri Banjarmasin.

Manfaat kegiatan penyuluhan penulisan surat lamaran pekerjaan dan praktik penulisannya pada siswa SMA Korpri Banjarmasin ini adalah:

1. Siswa SMA Korpri Banjarmasin diharapkan dapat memperoleh informasi mengenai lowongan pekerjaan, terutama informasi resmi, informasi dari iklan, informasi dari sumber lain, dan tanpa informasi dengan baik.

2. Siswa SMA Korpri Banjarmasin diharapkan dapat memperoleh informasi mengenai cara melamar suatu pekerjaan, terutama melamar pekerjaan melalui telepon dan melamar pekerjaan melalui surat lamaran pekerjaan dengan baik.

3. Siswa SMA Korpri Banjarmasin diharapkan dapat memperoleh mengenai surat lamaran pekerjaan, terutama berkenaan dengan pengertian surat lamaran pekerjaan, fungsi surat lamaran pekerjaan, format surat lamaran pekerjaan, dan bagian-bagian surat lamaran pekerjaan dengan baik.

4. Siswa SMA Korpri Banjarmasin diharapkan dapat menulis surat lamaran pekerjaan, terutama surat lamaran pekerjaan berdasarkan informasi resmi, 
informasi dari iklan, informasi dari sumber lain, dan tanpa informasi dengan baik.

Target luaran kegiatan penyuluhan penulisan surat lamaran pekerjaan dan praktik penulisannya ini adalah siswa SMA Korpri Banjarmasin, khususnya siswa kelas III, pertama mengetahui informasi lowongan pekerjaan, kedua mengetahui cara melamar suatu pekerjaan, ketiga mengetahui pengertian surat lamaran pekerjaan, fungsi surat lamaran pekerjaan, format surat lamaran pekerjaan, serta bagian-bagian surat lamaran pekerjaan, dan keempat dapat menulis surat lamaran pekerjaan dengan baik dan benar. Kalau siswa bersangkutan sudah lulus dan melamar pekerjaan, diharapkan siswa dapat mengajukan lamaran pekerjaan dengan baik serta dapat diterima bekerja sesuai dengan bidang pekerjaan yang diinginkan.

Karena itu, bagi siswa sangatlah penting mengetahui mengenai informasi lowongan pekerjaan, cara melamar suatu pekerjaan, surat lamaran pekerjaan, dan penulisan surat lamaran pekerjaan dengan baik dan benar, baik pada suatu instansi pemerintah maupun swasta. Dengan mengetahui informasi lowongan pekerjaan, cara melamar suatu pekerjaan, surat lamaran pekerjaan, dan penulisan surat lamaran pekerjaan sejak di bangku sekolah (SMA) diharapkan siswa (kelak setelah lulus sekolah dan ingin melamar suatu pekerjaan) tidak mengalami hambatan manakala mengajukan lamaran pekerjaan dan diharapkan dapat diterima bekerja sesuai dengan bidang pekerjaan yang diinginkan.

\section{METODE KEGIATAN}

Dalam upaya mencapai tujuan kegiatan penyuluhan penulisan surat lamaran pekerjaan dan praktik penulisannya pada siswa SMA Korpri Banjarmasin ini, metode pelaksanaan yang digunakan yaitu:

1. Ceramah

Metode ceramah digunakan terutama dalam penyampaian materi baik yang berkenaan dengan informasi lowongan pekerjaan, cara melamar suatu pekerjaan, maupun yang berkenaan dengan penulisan surat lamaran pekerjaannya. Kemudian, agar penyampaian materi lebih mudah dipahami, metode ceramah ini dilengkapi dengan penggunaan LCD, laptop, dan bahan-bahan tertulis yang dibagikan kepada siswa selaku peserta penyuluhan.

2. Tanya jawab

Dalam proses penyampaian materi atau sesudah materi disampaikan, para siswa diberi kesempatan untuk bertanya. Dengan demikian siswa diharapkan levbih memmahami materi yang disampaikan, baik materi yang berkenaan pada saat penyampaian materi, siswa juga bisa bertanya kepada peserta dalam rangka mencek pemahaman terhadap materi yang disampaikan.

3. Praktik

Selain metode ceramah dan tanya jawab, dalam upaya mencapai tujuan kegiatan penyuluhan penulisan surat lamaran pekerjaan dan praktik 
penulisannya ini, metode yang juga digunakan yaitu praktik. Dalam hal ini, siswa praktik menulis surat lamaran pekerjaan. Dengan demikian akan dapat diketahui hasil penulisan surat lamaran pekerjaan yang ditulis oleh siswa.

\section{HASIL DAN PEMBAHASAN}

Kegiatan pengabdian kepada masyarakat, berupa penyuluhan penulisan surat lamaran pekerjaan dan praktik penulisannya pada siswa SMA Korpri Banjarmasin ini, dilaksanakan pada hari Rabu, tanggal 28 Agustus 2019, bertempat di SMA Korpri Banjarmasin, Jalan Tanjung I Perumnas Kayutangi Blok IV Banjarmasin.

Penyuluhan penulisan surat lamaran pekerjaan dan praktik penulisannya pada siswa SMA Korpri Banjarmasin ini dihadiri oleh siswa SMA Korpri Banjarmasin, khususnya siswa Kelas III. Tim penyuluh sebanyak 4 orang. Mahasiswa yang ikut penyuluhan sebanyak 2 orang. Jumlah siswa (sebagai peserta) yang hadir sebanyak 20 orang.

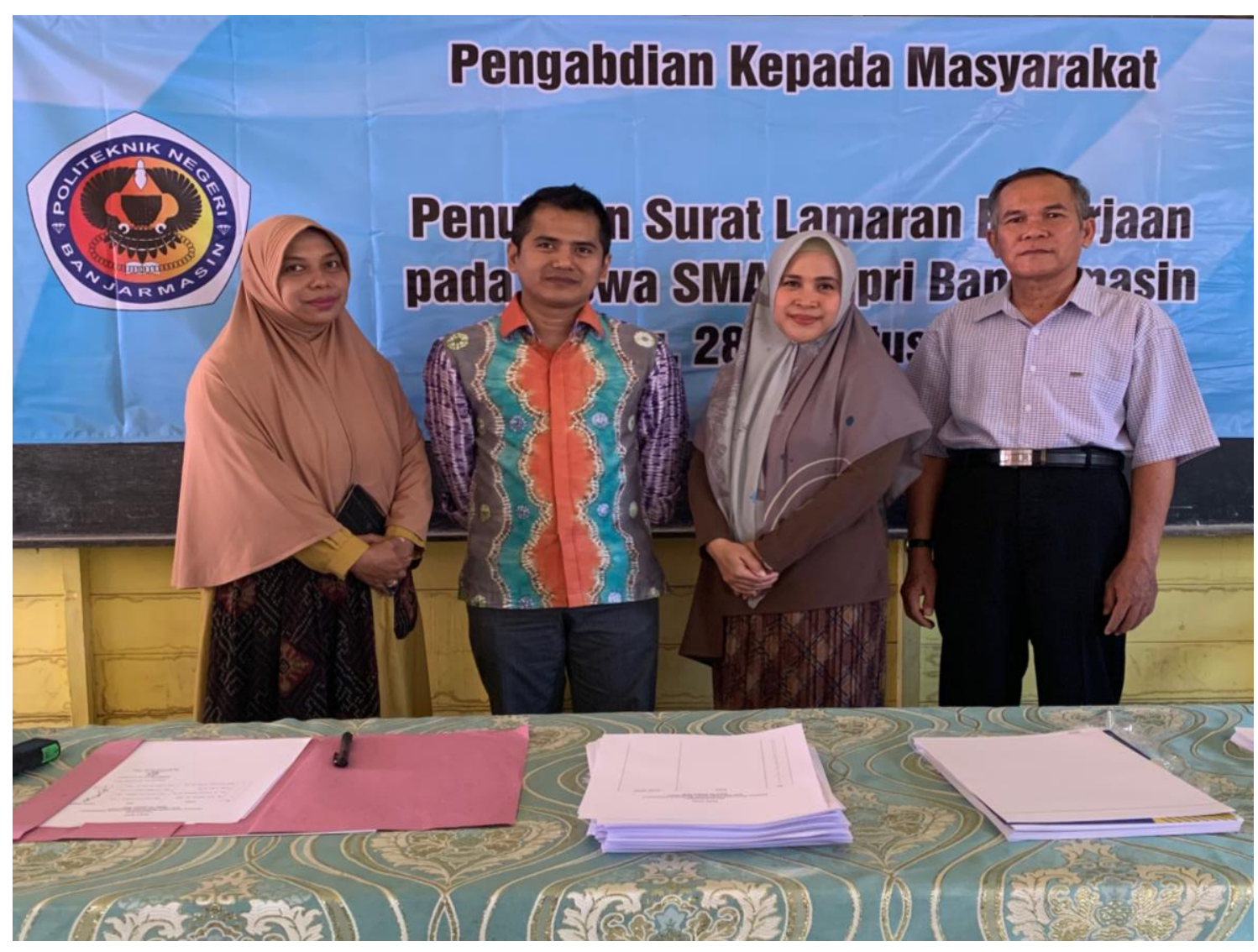

Gambar 1. Tim Penyuluh 
Penyuluhan disampaikan dengan metode ceramah, tanya jawab, dan praktik penulisan surat lamaran pekerjaan oleh para siswa (sebagai peserta penyuluhan).

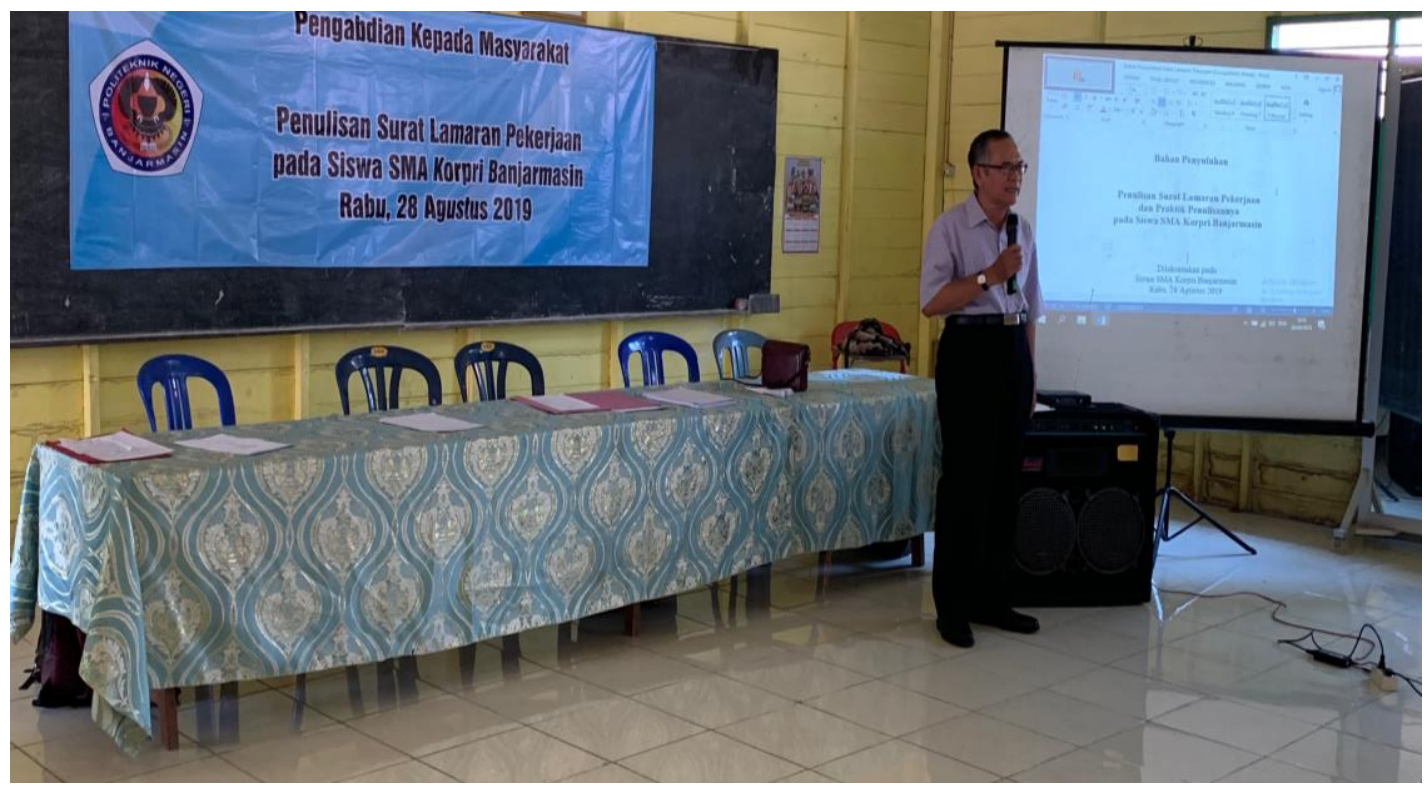

Gambar 2. Pelaksanaan Penyuluhan

Hasil dan luaran yang dicapai dalam kegiatan pengabdian kepada masyarakat, berupa penyuluhan penulisan surat lamaran pekerjaan dan praktik penulisannya pada siswa SMA Korpri Banjarmasin ini, khususnya bagi siswa kelas III sebagai peserta penyuluhan, setidak-tidaknya ada empat hasil yang telah dicapai:

Pertama, siswa SMA Korpri Banjarmasin dapat mengetahui dengan baik mengenai informasi lowongan pekerjaan, terutama informasi resmi, informasi dari iklan, informasi dari sumber lain, dan tanpa informasi.

Kedua, siswa SMA Korpri Banjarmasin dapat mengetahui dengan baik mengenai cara melamar suatu pekerjaan, terutama melamar pekerjaan melalui telepon dan melamar pekerjaan melalui surat lamaran pekerjaan.

Ketiga, siswa SMA Korpri Banjarmasin dapat mengetahui dengan baik mengenai surat lamaran pekerjaan, terutama berkenaan dengan pengertian surat lamaran pekerjaan, fungsi surat lamaran pekerjaan, format surat lamaran pekerjaan, dan bagian-bagian surat lamaran pekerjaan, yaitu bagian pembuka, isi dan penutup. (Suparjati, dkk. 2000.)

Keempat, siswa SMA Korpri Banjarmasin dapat menulis surat lamaran pekerjaan dengan baik, terutama surat lamaran pekerjaan berdasarkan informasi resmi, informasi dari iklan, informasi dari sumber lain, dan tanpa informasi.

Khusus mengenai surat lamaran pekerjaan yang telah ditulis oleh siswa SMA Korpri Banjarmasin, terutama oleh siswa kelas III sebagai peserta penyuluhan, tampak bahwa siswa memang dapat menulis surat lamaran pekerjaan pada saat praktik. 


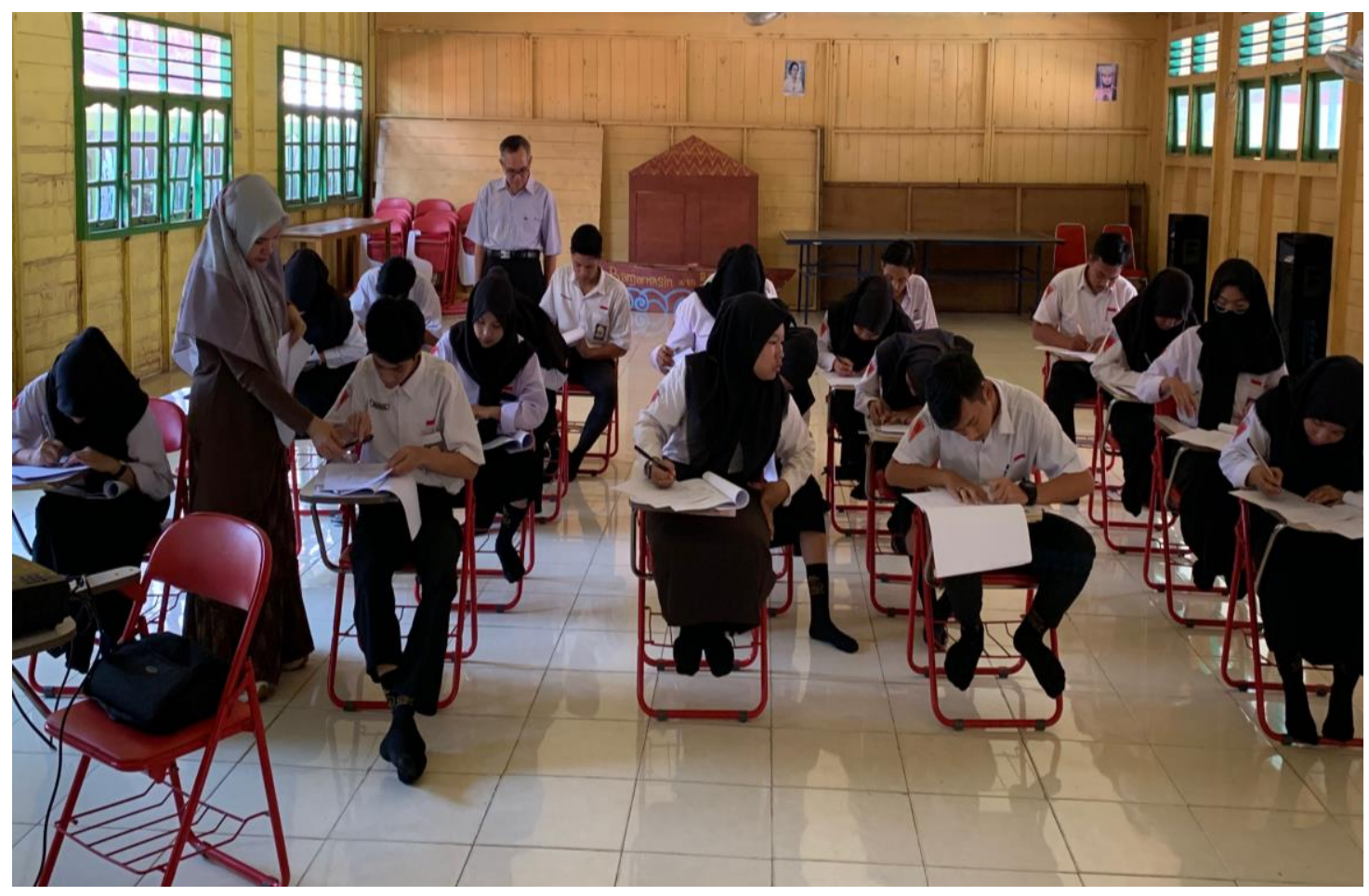

Gambar 3. Praktik Penulisan Surat Lamaran Pekerjaan

\section{KESIMPULAN}

Berdasarkan hasil pelaksanaan penyuluhan penulisan surat lamaran pekerjaan dan praktik penulisannya pada siswa SMA Korpri Banjarmasin dapat disimpulkan bahwa siswa SMA Korpri Banjarmasin, khususnya siswa kelas III, sebagai peserta penyuluhan penulisan surat lamaran pekerjaan dan praktik penulisannya telah :

1. Mengetahui informasi mengenai lowongan pekerjaan, terutama informasi resmi, informasi dari iklan, informasi dari sumber lain, dan tanpa informasi kepada siswa SMA Korpri Banjarmasin.

2. Mengetahui mengenai tata cara melamar suatu pekerjaan, terutama melamar pekerjaan melalui telepon dan melamar pekerjaan melalui surat lamaran pekerjaan kepada siswa SMA Korpri Banjarmasin.

3. Mengetahui informasi mengenai surat lamaran pekerjaan, khususnya yang berkenaan dengan pengertian surat lamaran pekerjaan, fungsi surat lamaran pekerjaan, format surat lamaran pekerjaan, dan bagian-bagian surat lamaran pekerjaan kepada siswa SMA Korpri Banjarmasin.

4. Mengetahui informasi mengenai cara menulis surat lamaran pekerjaan, terutama surat lamaran pekerjaan berdasarkan informasi resmi, informasi dari iklan, informasi dari sumber lain, dan tanpa informasi kepada siswa SMA Korpri Banjarmasin. 


\section{SARAN}

Sehubungan dengan kesimpulan berkenaan dengan hasil pelaksanaan penyuluhan penulisan surat lamaran pekerjaan dan praktik penulisannya pada siswa SMA Korpri Banjarmasin seperti dikemukakan di atas, khususnya bagi siswa kelas III sebagai peserta penyuluhan, dapat dikemukakan saran-saran sebagai berikut:

1. Sebaiknya siswa SMA Korpri Banjarmasin, khusus bagi siswa kelas III, dapat lebih jauh mengetahui mengenai informasi lowongan pekerjaan, terutama dengan melihat serta mengetahui secara langsung dari beberapa informasi lowongan pekerjaan.

2. Sebaiknya siswa SMA Korpri Banjarmasin, khusus bagi siswa kelas III, dapat mempraktikkan cara melamar suatu pekerjaan, misalnya di kelas masing-masuing atau di sekolah dengan dipandu oleh (para) guru, baik berkenaan dengan melamar pekerjaan melalui telepon maupun melamar pekerjaan melalui surat lamaran pekerjaan.

3. Sebaiknya siswa SMA Korpri Banjarmasin, khusus bagi siswa kelas III, setelah mengetahui mengenai surat lamaran pekerjaan, baik berkenaan dengan pengertian surat lamaran pekerjaan, fungsi surat lamaran pekerjaan, format surat lamaran pekerjaan, maupun bagian-bagian surat lamaran pekerjaan, dapat mempraktikkan sendiri dalam menulis surat lamaran pekerjaan.

4. Siswa SMA Korpri Banjarmasin, khusus bagi siswa kelas III, agar surat lamaran pekerjaan yang sudah pernah ditulis pada saat praktik dalam penyuluhan ini, dapat terus dipraktikkan serta ditingkatkan dalam penulisaannya sehingga (setelah lulus) apabila melamar suatu pekerjaan dapat melamar suatu pekerjaan dengan baik.

\section{DAFTAR PUSTAKA}

Arifin, E.Z., 1990. Pengunaan bahasa Indonesia dalam Surat Dinas. Mediyatama Sarana Perkasa.

Arifin, E.Z. dan Mustakim. 1994. Bahasa yang Efektif dalam Surat Lamaran. Jakarta: Penerbit Akademika Pressindo.

Arifin, Z., 2005. Bahasa Indonesia Bagi Sekretaris. Grasindo.

Pusat Pembinaan dan Pengembahan Bahasa. 1991. Seri Penyuluhan: SuratMenyurat dalam Bahasa Indonesia. Jakarta.

Suparjati, D., 2000. Surat Menyurat Dalam Perkantoran. Kanisius: Yogyakarta. 